\title{
Complete genome sequence of Ferrimonas balearica type strain (PAT ${ }^{\mathrm{T}}$ )
}

\author{
Matt Nolan' ${ }^{1}$, Johannes Sikorski ${ }^{2}$, Karen Davenport ${ }^{1,3}$, Susan Lucas ${ }^{1}$, Tijana Glavina Del Rio ${ }^{1}$, \\ Hope Tice ${ }^{1}$, Jan-Fang Cheng ${ }^{1}$, Lynne Goodwin ${ }^{1,3}$, Sam Pitluck ${ }^{1}$, Konstantinos Liolios ${ }^{1}$, Natalia \\ Ivanova ${ }^{1}$, Konstantinos Mavromatis ${ }^{1}$, Galina Ovchinnikova ${ }^{1}$, Amrita Pati ${ }^{1}$, Amy Chen ${ }^{4}$, \\ Krishna Palaniappan ${ }^{4}$, Miriam Land ${ }^{1,5}$, Loren Hauser ${ }^{1,5}$, Yun-Juan Chang ${ }^{1,5}$, Cynthia D. Jef- \\ fries $^{1,5}$, Roxanne Tapia ${ }^{1,3}$, Thomas Brettin ${ }^{1,3}$, John C. Detter ${ }^{1,3}$, Cliff Han ${ }^{1,3}$, Montri Yasa- \\ wong $^{6}$, Manfred Rohde ${ }^{6}$, Brian J Tindall ${ }^{2}$, Markus Göker ${ }^{2}$, Tanja Woyke ${ }^{1}$, James Bristow ${ }^{1}$, Jo- \\ nathan A. Eisen ${ }^{1,7}$, Victor Markowitz ${ }^{4}$, Philip Hugenholtz ${ }^{1}$, Nikos C. Kyrpides ${ }^{1}$, Hans-Peter \\ Klenk $^{2^{*}}$, and Alla Lapidus ${ }^{1}$ \\ ${ }^{1}$ DOE Joint Genome Institute, Walnut Creek, California, USA \\ ${ }^{2}$ DSMZ - German Collection of Microorganisms and Cell Cultures GmbH, Braunschweig, \\ Germany \\ ${ }^{3}$ Los Alamos National Laboratory, Bioscience Division, Los Alamos, New Mexico, USA \\ ${ }^{4}$ Biological Data Management and Technology Center, Lawrence Berkeley National Labora- \\ tory, Berkeley, California, USA \\ ${ }^{5}$ Oak Ridge National Laboratory, Oak Ridge, Tennessee, USA \\ ${ }^{6} \mathrm{HZI}$ - Helmholtz Centre for Infection Research, Braunschweig, Germany \\ ${ }^{7}$ University of California Davis Genome Center, Davis, California, USA \\ ${ }^{*}$ Corresponding author: Hans-Peter Klenk
}

Keywords: chemoorganotroph, iron(III)-reducing bacterium, facultatively anaerobic, Ferrimonadaceae, Gammaproteobacteria, GEBA

Ferrimonas balearica Rossello-Mora et al. 1996 is the type species of the genus Ferrimonas,
which belongs to the family Ferrimonadaceae within the Gammaproteobacteria. The species
is a Gram-negative, motile, facultatively anaerobic, non spore-forming bacterium, which is of
special interest because it is a chemoorganotroph and has a strictly respiratory metabolism
with oxygen, nitrate, Fe(III)-oxyhydroxide, Fe(III)-citrate, $\mathrm{MnO}_{2}$, selenate, selenite and thiosul-
fate as electron acceptors. This is the first completed genome sequence of a member of the
genus Ferrimonas and also the first sequence from a member of the family Ferrimonadaceae.
The $4,279,159$ bp long genome with its 3,803 protein-coding and 144 RNA genes is a part of
the Genomic Encyclopedia of Bacteria and Archaea project.

\section{Introduction}

Strain PAT ${ }^{\mathrm{T}}$ (= DSM $9799=$ CCM 4581) is the type strain of the species Ferrimonas balearica, which is the type species of its genus Ferrimonas [1,2]. Currently, there are five species in the genus Ferrimonas [3]. The generic name derives from the Latin word 'ferrum' meaning 'iron' and the Greek word 'monas' meaning 'unit', referring to an iron(III)-reducing cell. The species epithet is also derived from the Latin word 'balearica' meaning 'of the Balearic Islands', referring to the place where the strain was isolated [1]. Ferrimonas is the type genus of the family Ferrimonadaceae and one of two genera in the family Ferrimonadaceae
[4]. Strain PAT ${ }^{\mathrm{T}}$ was described in 1995 by Rossello-Mora et al. [1] who isolated the strain from the upper few centimeters of marine sediment of the Palma de Mallorca harbor, Spain [1,5]. Here we present a summary classification and a set of features for F. balearica PAT', together with the description of the complete genomic sequencing and annotation.

\section{Classification and features}

The 16S rRNA gene sequence of PAT ${ }^{\mathrm{T}}$ is 99\% identical to four culturable strains, which are reported 
in GenBank [6]. Two strains, A2A-18 (AB193752) and A3B-47-3 (AB193753), were isolated from marine sand [7]. The culturable strain S8-05 (EU620413) was isolated from Palk Bay sediment in Thondi, India and another strain with accession number AY158002 was isolated from Ala Wai Canal sediment in Honolulu, USA. The 16S rRNA gene of strain PAT ${ }^{\mathrm{T}}$ shares $93.5-97.4 \%$ sequence identity with the sequences of the type strains from the other members of the family Ferrimonadaceae [8]. The environmental samples database (env_nt) contains the marine metagenome clone 1096626783183 (96\% sequence identity, AACY020355234). The genomic survey sequences database (gss) contains the uncultured bacterium clone BYUP987.b1 (92\%, EF996742), isolated from a fecal sample of adult woman who gave birth after 11 months [9]. Altogether, strains belonging to the species $F$. balearica or the genus Ferrimonas are rather rare in the habitats screened so far (status September 2010).

Figure 1 shows the phylogenetic neighborhood of F. balearica PATT $^{\mathrm{T}}$ in a $16 \mathrm{~S}$ rRNA based tree. The sequences of the seven $16 \mathrm{~S}$ rRNA gene copies in the genome differ from each other by up to five nucleotides, and differ by up to four nucleotides from the previously published sequence (X93021), which contains two ambiguous base calls.

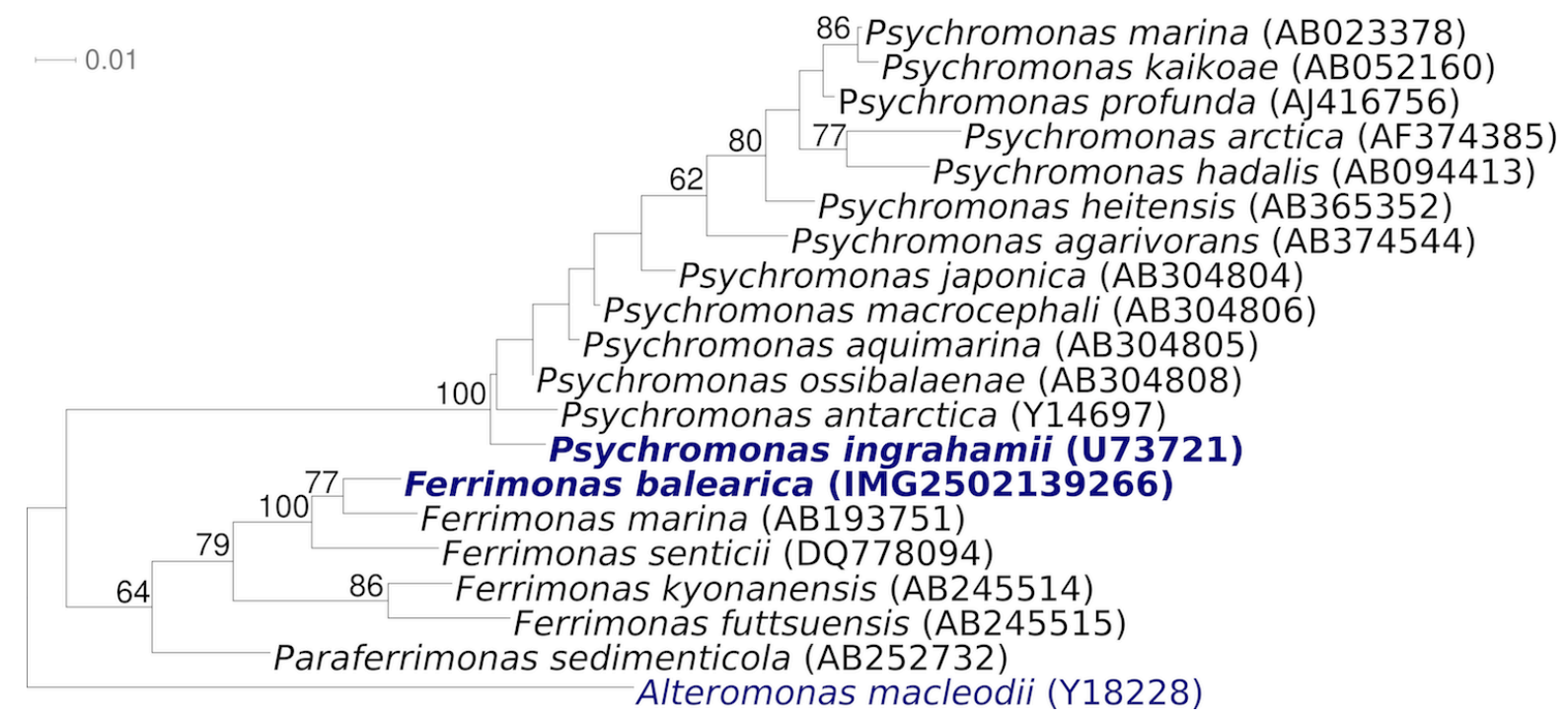

Figure 1. Phylogenetic tree highlighting the position of $F$. balearica $\mathrm{PAT}^{\top}$ relative to the type strains of the other species within the family Ferrimonadaceae and to the type of the neighboring family Psychromonadaceae. The trees were inferred from 1,449 aligned characters [10,11] of the 16S rRNA gene sequence under the maximum likelihood criterion [12] and rooted with the type strain of the order Alteromonadaceae. The branches are scaled in terms of the expected number of substitutions per site. Numbers above branches are support values from 650 bootstrap replicates [13] if larger than 60\%. Lineages with type strain genome sequencing projects registered in GOLD [14] are shown in blue, published genomes in bold (CP000510) [15].

Strain PAT ${ }^{\mathrm{T}}$ is a Gram-negative, nonspore-forming, facultatively anaerobic bacterium [1]. The cells are straight rods $(0.3-0.5 \times 1.2-1.5 \mu \mathrm{m})$ with rounded ends (Figure 2, Table 1) [1,5] and appear singly, occasionally in pairs or short chains and usually not encapsulated $[1,5]$. Strain PATT is motile by means of monotrichous flagella (not visible in Figure 2 , but $10 \%$ of the cells in the original liquid culture were highly motile) [1]. Colonies produce a black iron precipitate when the cells are grown on TSI agar [1]. Although initially isolated using
TSI based media this strain grows better on Marine Broth. Colonies are often brown and mucous when the cells are grown under aerobic conditions [5]. Fresh isolates of this species may not form colonies on PYG agar medium, but the colonies are formed after several subcultivations in enrichment medium $[1,5]$. Resting stages of strain PAT $^{\mathrm{T}}$ are not known [5]. Cells of the strain undergo autolysis within five days under aerobic conditions $[1,5]$. Strain PAT $^{\text {T }}$ does not contain polyhydroxybutyrate (PHB) or other intracellular inclu- 
sions [2]. The strain is chemoorganotrophic. Under anaerobic conditions, the reduction of Fe(III)oxyhydroxide is coupled to the utilization of lactate as the electron donor, which yields magnetite $[1,5]$. Strain PAT $^{\mathrm{T}}$ uses oxygen, nitrate, Fe(III)oxyhydroxide, $\mathrm{Fe}(\mathrm{III})$-citrate, $\mathrm{MnO}_{2}$, selenate, selenite and thiosulfate as electron acceptors $[1,5,25]$. Strain PAT $^{\mathrm{T}}$ requires a minimum of $0.5 \%$ $\mathrm{NaCl}$ for growth, with a range of $\mathrm{NaCl}$ tolerance of $0.5 \%-7.5 \%$ [1]. It does not grow at $5^{\circ} \mathrm{C}$ or $44^{\circ} \mathrm{C}$ but does grow at $42^{\circ} \mathrm{C}$ [1]. The $\mathrm{pH}$ range for growth is 6-9 [1]. Enzymatic reactions are positive for catalase, oxidase, phenylalanine deaminase, DNAse and lipase (Tween 20 and Tween 80), but negative for amylase, arginine dihydrolase, gelatinase, lysine decarboxylase, Simmons citrate and urease $[1,5]$. The strain does not hydrolyze starch [1]. The genus Ferrimonas can be distinguished from other strictly respiratory Gram-negative genera of the Gammaproteobacteria based on its ability to reduce $\mathrm{Fe}(\mathrm{III})$, denitrification, growth at $42^{\circ} \mathrm{C}$, presence of phenylalanine deaminase activity, inability to grow in NaCL-free media, lack of gelatinase, urease and a negative reaction of Simmons citrate test [5].

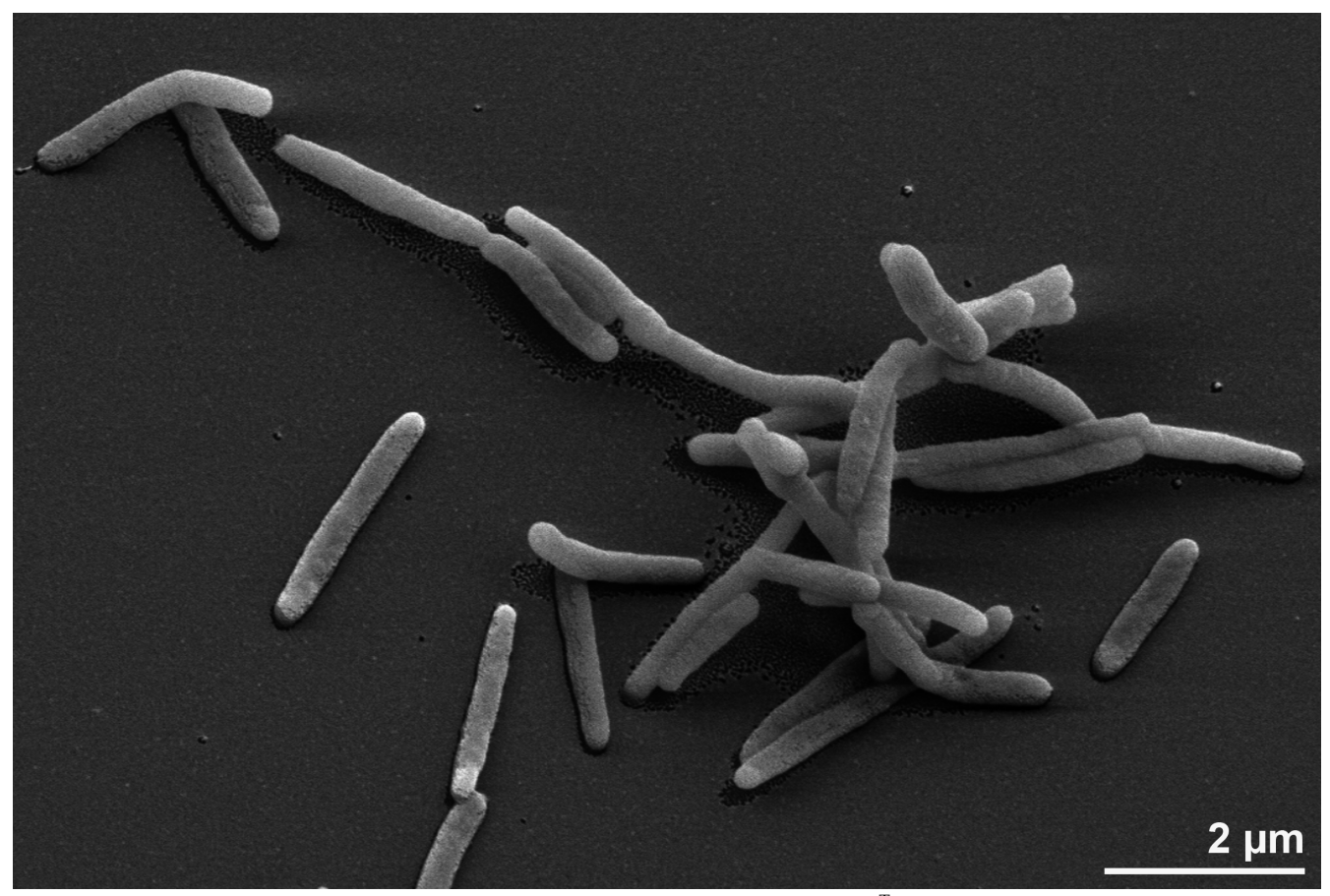

Figure 2. Scanning electron micrograph of $F$. balearica $\mathrm{PAT}^{\top}$

\section{Chemotaxonomy}

The quinone profiles of strain PAT ${ }^{\mathrm{T}}$ are MK-7 (62.9\%), Q-8 (20.4\%) and Q-7 (16\%) [7]. The presence of both menaquinones and ubiquinones being indicative of the ability of this organism to grow aerobically (with ubiquinones) and anaerobically (with menaquinones). The presence of menaquinones and ubiquinones with different distributions of isoprenoid side chains is a feature also shared by members of the genus Shewanella [2628] and Paraferrimonas [29] The major cellular fatty acids of strain PATT, when grown on PYG medium, given in the original species description are $\mathrm{C}_{17: 1 \omega 8 c}(27.5 \%)$, iso- $\mathrm{C}_{15: 0}(14.5 \%), \mathrm{C}_{17: 0}(7.8 \%)$, iso- $\mathrm{C}_{13: 0}(5.8 \%), \mathrm{C}_{16: 1 \omega 7 c}(4.7 \%), \mathrm{C}_{15: 0}(4.5 \%), \mathrm{C}_{13: 0}$
(4.5\%), $\mathrm{C}_{14: 0}(4.2 \%), \mathrm{C}_{18: 1 \omega 9 c}(4.0 \%)$ and $\mathrm{C}_{12: 0} 3-\mathrm{OH}$ (1.8\%), $\mathrm{C}_{17: 1 \omega 6 \mathrm{c}}(1.6 \%)$ and $\mathrm{C}_{18: 1 \omega 7 \mathrm{c}}(1.2 \%)$ [1]. More recent data show a somewhat different fatty acid pattern [7], with the fatty acids comprising iso- $\mathrm{C}_{15: 0}$ (9.8\%), $\mathrm{C}_{15: 0}(1.8 \%)$ iso- $\mathrm{C}_{16: 1 \omega 9 \mathrm{c}}(10.4 \%)$ iso- $\mathrm{C}_{16: \omega 7 \mathrm{c}}(5.2 \%), \mathrm{C}_{16: 0}(13.4 \%)$ iso- $\mathrm{C}_{17: 0}(2.1 \%)$

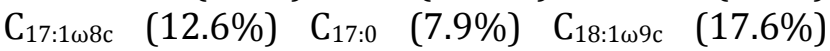
$\mathrm{C}_{18: 1 \omega 7 \mathrm{c}}(4.9 \%)$ and $\mathrm{C}_{18: 0}(3.9 \%)$. Hydroxylated fatty acids were not reported. Interestingly the fatty acids reported in a subsequent paper [25] that are based on the work of Kasuta et al. [7] omit the iso$\mathrm{C}_{16: 1}$ fatty acids. The fatty acids reported in the original publication [1] show a number of features also found in members of the genera Shewanella 
and Paraferrimonas [29,30]. Data generated in the DSMZ during the course of this work indicates that the fatty acids comprise, iso- $\mathrm{C}_{13: 0}(3.7 \%), \mathrm{C}_{13: 0}$ (2.7\%), $\mathrm{C}_{12: 0} 30 \mathrm{H}(2.2 \%)$, iso- $\mathrm{C}_{14: 0}(1.1 \%), \mathrm{C}_{14: 0}$ (1.0\%), iso- $\mathrm{C}_{13: 0} 30 \mathrm{H}(3.7 \%), \mathrm{C}_{13: 0} 30 \mathrm{H}(1.9 \%)$, iso$\mathrm{C}_{15: 0}(16.1 \%), \mathrm{C}_{15: 1 \text { w8c }}(2.1 \%), \mathrm{C}_{15: 0}(4.5 \%), \mathrm{C}_{14: 0} 3-$ $\mathrm{OH}(2.9 \%), \mathrm{C}_{16: 1 \text { w9c }}(8.1 \%), \mathrm{C}_{16: 1 w 7 c}(4.9 \%), \mathrm{C}_{16: 0}$ (8.4\%), iso- $\mathrm{C}_{15: 0} 30 \mathrm{H},(0.9 \%)$, iso- $\mathrm{C}_{17: 0}(1.4 \%), \mathrm{C}_{17: 1}$ w8c $(14.7 \%), \mathrm{C}_{17: 0}(5.6 \%), \mathrm{C}_{18: 1}$ w9c $(7.8 \%)$ and $\mathrm{C}_{18: 1}$ w7c $(1.4 \%)$. These results are more consistent with those published in the original description [1], but there are differences that cannot be attributed to differences in the growth conditions. The complete absence of hydroxylated fatty acids in the work of Kasuta et al. [7] suggests that no attempt was made to detect them. The presence of at least two positional isomers in unsaturated fatty acids with the same chain length is indicative of the presence of at least two enzymatic pathways for introducing the double bonds. A fairly simple polar lipid pattern has been reported for Ferrimonas futtsuensis, comprising, phosphatidylglycerol, phosphatidylethanolamine and an unidentified aminophopsholipid [29].

Table 1. Classification and general features of $F$. balearica PAT ${ }^{\top}$ according to the MIGS recommendations [16].

\begin{tabular}{|c|c|c|c|}
\hline MIGS ID & Property & Term & Evidence code \\
\hline & \multirow{8}{*}{ Current classification } & Domain Bacteria & TAS [17] \\
\hline & & Phylum Proteobacteria & TAS [18-20] \\
\hline & & Class Gammaproteobacteria & TAS $[18,21]$ \\
\hline & & Order Alteromonadales & TAS $[18,22]$ \\
\hline & & Family Ferrimonadaceae & TAS [4] \\
\hline & & Genus Ferrimonas & TAS $[1,2]$ \\
\hline & & Species Ferrimonas balearica & TAS $[1,2]$ \\
\hline & & Type strain PAT & TAS $[1,2]$ \\
\hline & Gram stain & negative & TAS [1] \\
\hline & Cell shape & straight rods with rounded ends & TAS $[1,5]$ \\
\hline & Motility & yes & TAS [1] \\
\hline & Sporulation & nonspore-forming & TAS [1] \\
\hline & Temperature range & $37^{\circ} \mathrm{C}-42^{\circ} \mathrm{C}$ & TAS $[1,5]$ \\
\hline & Optimum temperature & $37^{\circ} \mathrm{C}$ & NAS \\
\hline & Salinity & $0.5 \%-7.5 \%(\mathrm{w} / \mathrm{v}) \mathrm{NaCl}$ & TAS $[1,5]$ \\
\hline \multirow[t]{3}{*}{ MIGS-22 } & Oxygen requirement & facultatively anaerobic & TAS [1] \\
\hline & Carbon source & lactate & TAS [1] \\
\hline & Energy source & chemoorganotroph & TAS $[1,5]$ \\
\hline MIGS-6 & Habitat & marine sediment & TAS [1] \\
\hline MIGS-15 & Biotic relationship & free-living & NAS \\
\hline \multirow[t]{3}{*}{ MIGS-14 } & Pathogenicity & none & NAS \\
\hline & Biosafety level & 1 & TAS [23] \\
\hline & Isolation & marine sediment & TAS [1] \\
\hline MIGS-4 & Geographic location & Palma de Mallorca harbor, Spain & TAS [1] \\
\hline MIGS-5 & Sample collection time & 1995 or before & TAS [1] \\
\hline MIGS-4.1 & Latitude & 39.57 & NAS \\
\hline MIGS-4.2 & Longitude & 2.63 & NAS \\
\hline MIGS-4.3 & Depth & not report & \\
\hline MIGS-4.4 & Altitude & below the sea level & TAS $[1,5]$ \\
\hline
\end{tabular}

Evidence codes - IDA: Inferred from Direct Assay (first time in publication); TAS: Traceable Author Statement (i.e., a direct report exists in the literature); NAS: Non-traceable Author Statement (i.e., not directly observed for the living, isolated sample, but based on a generally accepted property for the species, or anecdotal evidence). These evidence codes are from of the Gene Ontology project [24]. If the evidence code is IDA, then the property was directly observed by one of the authors or an expert mentioned in the acknowledgements. 


\section{Genome sequencing and annotation \\ Genome project history}

This organism was selected for sequencing on the basis of its phylogenetic position [31], and is part of the Genomic Encyclopedia of Bacteria and Archaea project [32]. The genome project is deposited in the Genome OnLine Database [14] and the complete genome sequence is deposited in GenBank. Sequencing, finishing and annotation were performed by the DOE Joint Genome Institute (JGI). A summary of the project information is shown in Table 2.

Table 2. Genome sequencing project information

\begin{tabular}{|c|c|c|}
\hline MIGS ID & Property & Term \\
\hline MIGS-31 & Finishing quality & Finished \\
\hline MIGS-28 & Libraries used & $\begin{array}{l}\text { Two genomic Sanger libra- } \\
\text { ries: } 8 \mathrm{~kb} \text { pMCL200 library, } \\
\text { fosmid ( } 40 \mathrm{~kb} \text { ) library }\end{array}$ \\
\hline MIGS-29 & Sequencing platforms & $\mathrm{ABI} 3730$ \\
\hline MIGS-31.2 & Sequencing coverage & $9.8 \times$ Sanger \\
\hline MIGS-30 & Assemblers & Phrap \\
\hline \multirow[t]{6}{*}{ MIGS-32 } & Gene calling method & Prodigal 1.4, GenePRIMP \\
\hline & INSDC ID & СР002209 \\
\hline & Genbank Date of Release & October 1, 2010 \\
\hline & GOLD ID & Gc01378 \\
\hline & NCBI project ID & 30799 \\
\hline & Database: IMG-GEBA & 2502082106 \\
\hline \multirow[t]{2}{*}{ MIGS-13 } & Source material identifier & DSM 9799 \\
\hline & Project relevance & Tree of Life, GEBA \\
\hline
\end{tabular}

\section{Growth conditions and DNA isolation}

F. balearica PAT ${ }^{\mathrm{T}}$, DSM 9799, was grown in DSMZ medium 514 (Bacto Marine Broth) [33] at $28^{\circ} \mathrm{C}$. DNA was isolated from $0.5-1 \mathrm{~g}$ of cell paste using Qiagen Genomic 500 DNA Kit (Qiagen, Hilden, Germany) following the standard protocol as recommended by the manufacturer, with modification st/L for cell lysis as described in Wu et al. [32].

\section{Genome sequencing and assembly}

The genome was sequenced using the Sanger sequencing platform (6 and $40 \mathrm{~kb}$ DNA libraries). All general aspects of library construction and sequencing performed at the JGI can be found at http://www.jgi.doe.gov/. The Phred/Phrap/Consed software package was used for sequence assembly and quality assessment. After the shotgun stage, reads were assembled with parallel phrap (High Performance Software, LLC). Possible misassemblies were corrected with Dupfinisher or transposon bombing of bridging clones (Epicentre Biotechnologies, Madison, WI) [34]. Gaps between contigs were closed by editing in Consed, custom primer walk or PCR amplification. A total of 404 additional custom primer reactions were necessary to close gaps and to raise the quality of the finished sequence. The completed genome sequence contains 48,554 reads, achieving an average of 9.8-fold sequence coverage with an error rate less than 1 in 100,000 .

\section{Genome annotation}

Genes were identified using Prodigal [35] as part of the Oak Ridge National Laboratory genome annotation pipeline, followed by a round of manual curation using the JGI GenePRIMP pipeline [36]. The predicted CDSs were translated and used to search the National Center for Biotechnology Information (NCBI) nonredundant database, UniProt, TIGRFam, Pfam, PRIAM, KEGG, COG, and InterPro databases. Additional gene prediction analysis and functional annotation was performed within the Integrated Microbial Genomes Expert Review (IMG-ER) platform [37].

\section{Genome properties}

The genome consists of a 4,279,159 bp long chromosome with a $60.2 \%$ GC content (Table 3 and Figure 3). Of the 3,947 genes predicted, 3,803 were protein-coding genes, and 144 RNAs; twenty one pseudogenes were also identified. The majority of the protein-coding genes $(72.5 \%)$ were assigned a putative function while the remaining ones were annotated as hypothetical proteins. The distribution of genes into COGs functional categories is presented in Table 4. 
Table 3. Genome Statistics

\begin{tabular}{lrr}
\hline Attribute & Value & \% of Total \\
\hline Genome size (bp) & $4,279,159$ & $100.00 \%$ \\
DNA coding region (bp) & $3,842,563$ & $89.80 \%$ \\
DNA G+C content (bp) & $2,576,887$ & $60.22 \%$ \\
Number of replicons & 1 & \\
Extrachromosomal elements & 0 & \\
Total genes & 3,947 & $100.00 \%$ \\
RNA genes & 144 & $3.65 \%$ \\
rRNA operons & 7 & \\
Protein-coding genes & 3,803 & $96.35 \%$ \\
Pseudo genes & 21 & $0.53 \%$ \\
Genes with function prediction & 2,860 & $72.46 \%$ \\
Genes in paralog clusters & 462 & $11.71 \%$ \\
Genes assigned to COGs & 2,929 & $74.21 \%$ \\
Genes assigned Pfam domains & 3,089 & $78.26 \%$ \\
Genes with signal peptides & 1,154 & $29.24 \%$ \\
Genes with transmembrane helices & 981 & $24.85 \%$ \\
CRISPR repeats & 0 & \\
\hline
\end{tabular}

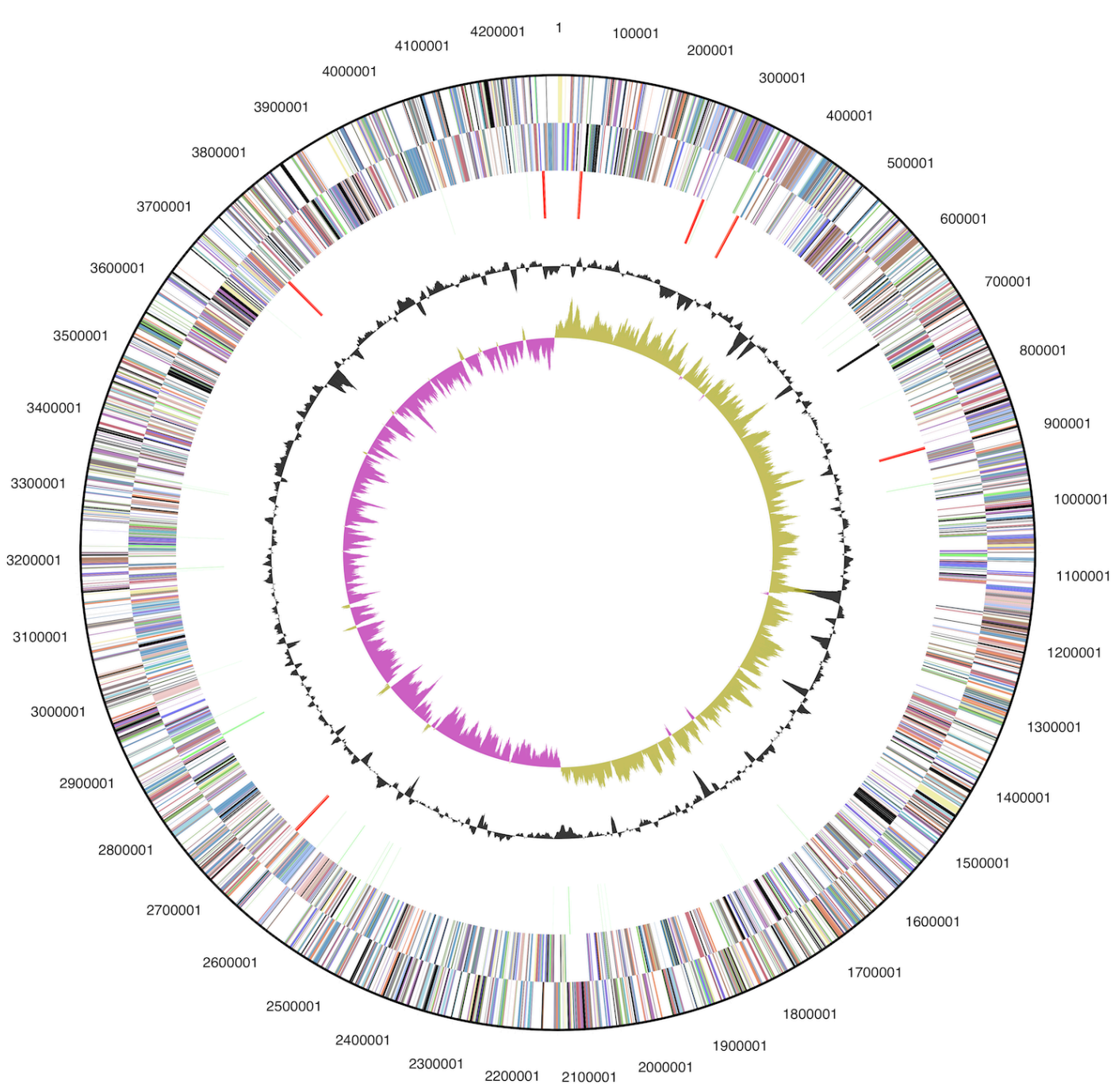

Figure 3. Graphical circular map of the genome. From outside to the center: Genes on forward strand (color by COG categories), Genes on reverse strand (color by COG categories), RNA genes (tRNAs green, rRNAs red, other RNAs black), GC content, GC skew. 
Table 4. Number of genes associated with the general COG functional categories

\begin{tabular}{lrrl}
\hline Code & value & \%age & Description \\
\hline J & 189 & 5.8 & Translation, ribosomal structure and biogenesis \\
A & 1 & 0.0 & RNA processing and modification \\
K & 213 & 6.5 & Transcription \\
L & 138 & 4.2 & Replication, recombination and repair \\
B & 1 & 0.0 & Chromatin structure and dynamics \\
D & 35 & 1.1 & Cell cycle control, cell division, chromosome partitioning \\
Y & 0 & 0.0 & Nuclear structure \\
V & 61 & 1.9 & Defense mechanisms \\
T & 178 & 5.5 & Signal transduction mechanisms \\
M & 219 & 6.7 & Cell wall/membrane/envelope biogenesis \\
N & 133 & 4.1 & Cell motility \\
Z & 0 & 0.0 & Cytoskeleton \\
W & 0 & 0.0 & Extracellular structures \\
U & 128 & 3.9 & Intracellular trafficking and secretion, and vesicular transport \\
O & 155 & 4.8 & Posttranslational modification, protein turnover, chaperones \\
C & 238 & 7.3 & Energy production and conversion \\
G & 105 & 3.2 & Carbohydrate transport and metabolism \\
E & 248 & 7.6 & Amino acid transport and metabolism \\
F & 85 & 2.6 & Nucleotide transport and metabolism \\
H & 167 & 5.1 & Coenzyme transport and metabolism \\
I & 99 & 3.0 & Lipid transport and metabolism \\
P & 184 & 6.7 & Inorganic ion transport and metabolism \\
Q & 53 & 1.6 & Secondary metabolites biosynthesis, transport and catabolism \\
R & 338 & 10.4 & General function prediction only \\
S & 287 & 8.8 & Function unknown \\
- & 1,018 & 25.8 & Not in COGs \\
\hline
\end{tabular}

\section{Acknowledgements}

We would like to gratefully acknowledge the help of Regine Fähnrich for growing F. balearica cultures and Susanne Schneider for DNA extraction and quality analysis (both at DSMZ). This work was performed under the auspices of the US Department of Energy Office of Science, Biological and Environmental Research Program, and by the University of California, Lawrence Berkeley National Laboratory under contract No. DE-

\section{References}

1. Rossello-Mora R, Ludwig W, Kämpfer P, Amann $\mathrm{R}$, Schleifer KH. Ferrimonas balearica gen. nov., spec. nov., a new marine facultative Fe(III)reducing bacterium. Syst Appl Microbiol 1995; 18:196-202.

2. Validation List No. 56. Validation of publication of new names and new combinations previously effectively published outside the IJSEM. Int J Syst Bacteriol 1996; 46:362-363. doi:10.1099/00207713-46-1-362
AC02-05CH11231, Lawrence Livermore National Laboratory under Contract No. DE-AC52-07NA27344, and Los Alamos National Laboratory under contract No. DEAC02-06NA25396, UT-Battelle and Oak Ridge National Laboratory under contract DE-AC05-000R22725, as well as German Research Foundation (DFG) INST 599/1-2 and Thailand Research Fund Royal Golden Jubilee Ph.D. Program No. PHD/0019/2548 for MY.

3. Garrity G. NamesforLife. BrowserTool takes expertise out of the database and puts it right in the browser. Microbiol Today 2010; 7:1.

4. Ivanova EP, Flavier S, Christen R. Phylogenetic relationships among marine Alteromonas-like proteobacteria: emended description of the family Alteromonadaceae and proposal of Pseudoalteromonadaceae fam. nov., Colwelliaceae fam. nov., Shewanellaceae fam. nov., Moritellaceae 
fam. nov., Ferrimonadaceae fam. nov., Idiomarinaceae fam. nov. and Psychromonadaceae fam. nov. Int J Syst Evol Microbiol 2004; 54:17731788. PubMed doi:10.1099/ijs.0.02997-0

5. Rossello-Mora R, Kämpfer P, Ludwig W, Amann R, Schleifer KH. 2005. Genus IV. Ferrimonas, p. 454-456. In D. J. Brenner, N. R. Krieg, J. T. Staley, and G. M. Garrity (ed.), Bergey's Manual of Systematic Bacteriology, 2nd ed, vol. 2. Springer, New York.

6. Benson DA, Karsch-Mizrachi I, Lipman DJ, Ostell J, Sayers EW. GenBank. Nucleic Acids Res 2009; 37:D26-D31. PubMed doi:10.1093/nar/gkn723

7. Katsuta A, Adachi K, Matsuda S, Shizuri Y, Kasai H. Ferrimonas marina sp. nov. Int J Syst Evol Microbiol 2005; 55:1851-1855. PubMed doi:10.1099/ijs.0.63689-0

8. Chun J, Lee JH, Jung Y, Kim M, Kim S, Kim BK, Lim YW. EzTaxon: a web-based tool for the identification of prokaryotes based on $16 \mathrm{~S}$ ribosomal RNA gene sequences. Int / Syst Evol Microbiol 2007; 57:2259-2261. PubMed doi:10.1099/ijs.0.64915-0

9. Vaishampayan PA, Kuehl JV, Froula JL, Morgan J, Ochman H, Francino MP. Comparative metagenomics and population dynamics of the gut microbiota in mother and infant. Genome Biol Evol 2010; 2:53-66. PubMed doi:10.1093/gbe/evp057

10. Castresana J. Selection of conserved blocks from multiple alignments for their use in phylogenetic analysis. Mol Biol Evol 2000; 17:540-552. PubMed

11. Lee C, Grasso C, Sharlow MF. Multiple sequence alignment using partial order graphs. Bioinformatics 2002; 18:452-464. PubMed doi:10.1093/bioinformatics/18.3.452

12. Stamatakis $A$, Hoover $P$, Rougemont J. A rapid bootstrap algorithm for the RAxML Web servers. Syst Biol 2008; 57:758-771. PubMed doi:10.1080/10635150802429642

13. Pattengale ND, Alipour M, Bininda-Emonds ORP, Moret BME, Stamatakis A. How many bootstrap replicates are necessary? Lect Notes Comput Sci 2009; 5541:184-200. doi:10.1007/978-3-64202008-7_13

14. Liolios K, Chen IM, Mavromatis K, Tavernarakis N, Hugenholtz P, Markowitz VM, Kyrpides NC. The Genomes On Line Database (GOLD) in 2009: status of genomic and metagenomic projects and their associated metadata. Nucleic
Acids Res 2009; 38:D346-D354. PubMed

doi:10.1093/nar/gkp848

15. Auman AJ, Breezee JL, Gosink JJ, Kämpfer P, Staley JT. Psychromonas ingrahamii sp. nov., a novel gas vacuolate, psychrophilic bacterium isolated from Arctic polar sea ice. Int / Syst Evol Microbiol 2006; 56:1001-1007. PubMed doi:10.1099/ijs.0.64068-0

16. Field D, Garrity G, Gray T, Morrison N, Selengut J, Sterk P, Tatusova T, Thomson N, Allen MJ, Angiuoli $S V$, et al. The minimum information about a genome sequence (MIGS) specification. Nat Biotechnol 2008; 26:541-547. PubMed doi: $10.1038 /$ nbt1360

17. Woese CR, Kandler O, Wheelis ML. Towards a natural system of organisms: proposal for the domains Archaea, Bacteria, and Eucarya. Proc Natl Acad Sci USA 1990; 87:4576-4579. PubMed doi:10.1073/pnas.87.12.4576

18. Validation List No. 106. Validation of publication of new names and new combinations previously effectively published outside the IJSEM. Int I Syst Evol Microbiol 2005; 55:2235-2238. doi:10.1099/ijs.0.64108-0

19. Garrity GM, Bell JA, Lilburn T. 2005. Phylum XIV. Proteobacteria phyl. nov. In DJ Brenner, NR Krieg, JT Staley, and GM Garrity (eds), Bergey's Manual of Systematic Bacteriology, 2 nd ed, vol. 2. Springer, New York.

20. Garrity GM, Holt JG. The Road Map to the Manual. In: Garrity GM, Boone DR, Castenholz RW (eds), Bergey's Manual of Systematic Bacteriology, Second Edition, Volume 1, Springer, New York, 2001, p. 119-169.

21. Garrity GM, Bell JA, Lilburn T. 2005. Class III. Gammaproteobacteria class. nov., p. 1. In DJ Brenner, NR Krieg, JT Staley, and GM Garrity (eds), Bergey's Manual of Systematic Bacteriology, 2nd ed, vol. 2. Springer, New York.

22. Bowman JP, McMeekin TA. 2005. Order X. Alteromonadales ord. nov., p. 443. In D J Brenner, NR Krieg, JT Staley, and GM Garrity (eds), Bergey's Manual of Systematic Bacteriology, 2nd ed, vol. 2. Springer, New York.

23. Classification of bacteria and archaea in risk groups. TRBA 466.

24. Ashburner M, Ball CA, Blake JA, Botstein D, Butler $\mathrm{H}$, Cherry JM, Davis AP, Dolinski K, Dwight SS, Eppig JT, et al. Gene Ontology: tool for the unification of biology. Nat Genet 2000; 25:25-29. PubMed doi:10.1038/75556 
25. Nakagawa T, lino T, Suzuki K, Harayama S. Ferrimonas futtsuensis sp. nov. and Ferrimonas kyonanensis sp. nov., selenate-reducing bacteria belonging to the Gammaproteobacteria isolated from Tokyo Bay. Int I Syst Evol Microbiol 2006; 56:2639-2645. PubMed doi:10.1099/ijs.0.64399$\underline{0}$

26. Moule AL, Wilkinson SG. Polar lipids, fatty acids, and isoprenoid quinones of Alteromonas putrefaciens (Shewanella putre- faciens). Syst Appl Microbiol 1987; 9:192-198.

27. Akagawa-Matsushita M, Itoh T, Katayama Y, Kuraishi $\mathrm{H}$, Yamasato $\mathrm{K}$. Isoprenoid quinone composition of some marine Alteromonas, Marinomonas, Deleya, Pseudomonas and Shewanella species. J Gen Microbiol 1992; 138:2275-2281.

28. Frolova GM, Pavel KG, Shparteeva AA, Nedashkovskaya OI, Gorshkova NM, Ivanova EP, Mikhailov VV. Lipid composition of novel Shewanella species isolated from Far Eastern seas. Microbiology 2005; 74:664-669. doi:10.1007/s11021-005$\underline{0121-9}$

29. Khan ST, Harayama S. Paraferrimonas sedimenticola gen. nov., sp. nov., a marine bacterium of the family Ferrimonadaceae. Int J Syst Evol Microbiol 2007; 57:1493-1498. PubMed doi:10.1099/ijs.0.64529-0

30. Leonardo MR, Moser DP, Brabieri E, Brantner CA, MacGregor BJ, Paster BJ, Stackebrandt E. Nea1son KH. Shewanella pealeana sp. nov., a member of the microbial community associated with the accessory nidamental gland of the squid Loligo pealei. Int J Syst Bacteriol 1999; 49:13411351. PubMed doi:10.1099/00207713-49-4-1341
31. Klenk HP, Göker M. En route to a genome-based classification of Archaea and Bacteria? Syst Appl Microbiol 2010; 33:175-182. PubMed doi:10.1016/j.syapm.2010.03.003

32. Wu D, Hugenholtz P, Mavromatis K, Pukall R, Dalin E, Ivanova NN, Kunin V, Goodwin L, Wu $M$, Tindall BJ, et al. A phylogeny-driven genomic encyclopaedia of Bacteria and Archaea. Nature 2009; 462:1056-1060. PubMed doi:10.1038/nature08656

33. List of growth media used at DSMZ: http//www.dsmz.de/microorganisms/media_list.p hp.

34. Sims D, Brettin T, Detter JC, Han C, Lapidus A, Copeland A, Glavina Del Rio T, Nolan M, Chen $\mathrm{F}$, Lucas $\mathrm{S}$, et al. Complete genome sequence of Kytococcus sedentarius type strain $\left(541^{\mathrm{T}}\right)$. Stand Genomic Sci 2009; 1:12-20. doi:10.4056/sigs.761

35. Hyatt D, Chen GL, Locascio PF, Land ML, Larimer FW, Hauser LJ. Prodigal: prokaryotic gene recognition and translation initiation site identification. BMC Bioinformatics 2010; 11:119. PubMed doi:10.1186/1471-2105-11-119

36. Pati A, Ivanova NN, Mikhailova N, Ovchinnikova G, Hooper SD, Lykidis A, Kyrpides NC. GenePRIMP: a gene prediction improvement pipeline for prokaryotic genomes. Nat Methods 2010; 7:455-457. PubMed doi:10.1038/nmeth.1457

37. Markowitz VM, Ivanova NN, Chen IMA, Chu K, Kyrpides NC. IMG ER: a system for microbial genome annotation expert review and curation. Bioinformatics 2009; 25:2271-2278. PubMed doi:10.1093/bioinformatics/btp393 